Viewpoint

\section{A Rapidly Aging Population Requires an Optimal System of Care to Stop Alzheimer's Disease}

\author{
George Vradenburg \\ Chairman and co-founder of UsAgainstAlzheimer's, PO Box 34565, Washington, \\ DC 20043, USA. Email: vradenburg@usagainstalzheimers.org
}

Thanks to modern medicine and technology, people are living longer than ever before. The number of Americans age 65 and older is expected to grow 81 percent between 2010 and 2030-exponentially faster than any other age demographic. Consider that of all the people in human history who have lived past the age of 65, two-thirds of them are alive today [1].

With age the No. 1 risk-factor for Alzheimer's [2], the only leading cause of death in America without an effective treatment or cure, these demographic trendlines paint a stark picture. Barring the discovery of a new effective therapy or method of prevention-combined with the requisite structural updates to our healthcare system that must be undertaken if a cure is to do any good-the number of Americans living with Alzheimer's disease and dementia will continue to increase from 5.8 million today to an estimated 14 million by 2050 [3]. Unchecked, it will become the biggest public health crisis of the 21st century.

Steps are being taken to begin to change the course of this demographic trend. Federal funding for Alzheimer's research through the National Institutes of Health increased to $\$ 2.8$ billion this year [4]; advances are being made in drug therapies [5] to treat the disease, and emerging science [6] is demonstrating that actions can be taken to delay or prevent onset of the disease.

Despite these developments, the nation and the world are not ready for the growing Alzheimer's crisis.

UsAgainstAlzheimer's, a venture non-profit organization committed to accelerated action to find an effective treatment or prevention for Alzheimer's disease, looks at the fight against this disease from a broader context. In its work, it seeks to address various stakeholder perspectivesresearch, government policy, patients, caregivers, providers and government and private sector insurance payers-and how they all need to fit together in an overall strategy to stop Alzheimer's.

Specifically, UsAgainstAlzheimer's is advocating for the creation of an "optimal system of care" [7]. This ideal system operates under a "dualpath" pursuit of pharmacological and non-pharmacological interventions, and, at the same time, works to prepare existing healthcare infrastructure to properly implement and distribute an effective treatment or means of prevention.

For example, it is important to look beyond just drug-based solutions and explore all avenues of treatment or prevention. Emerging evidence 
suggests exercise, diet, sleep, smoking cessation, weight loss, cognitive training, stress reduction, and medical management of diabetes and hypertension may all have positive effects in potentially slowing and in some cases preventing cognitive decline [8,9].

At the same time, there are several disease-modifying drugs currently in the R\&D pipeline-with some expected to be submitted for review by the Food \& Drug Administration in 2020-that are designed for those with dementia at the earliest stages [10]. Slowing or preventing symptoms either before they occur or at their earliest stages would help improve quality of life; reduce financial, emotional, and social costs on patients, caregivers, and families; and buy time for additional research and development into other pharmacological and non-pharmacological interventions.

But if ultimately approved, these drugs will be practically useless if the healthcare system cannot identify those individuals in the early stages of the disease. Thus, to take advantage of this dual approach, the timely detection of cognitive impairment and diagnosis of Alzheimer's must be adopted as a national goal. This way, affirmative steps can be taken now to prepare for disease-modifying drugs coming to market in the future.

This is a crucial step. Unfortunately, neither the U.S. nor the global healthcare system is ready to connect those living with Alzheimer's disease to treatments and lifestyle interventions. Healthcare providers aren't ready to diagnosis those with or currently at risk for dementia. Payers aren't ready to reimburse for what may be the expensive earlystage drugs that could drive innovation. And patients aren't ready because they don't know what to ask their healthcare providers to do about maintaining or improving their brain health.

As the pursuit of both pharmacological and non-pharmacological Alzheimer's interventions continues, in preparation for their discovery, there are four components whose work can begin right now to prepare the U.S. and global healthcare systems for a cure. These components were developed by UsAgainstAlzheimer's in collaboration with more than 40 experts in the field.

First, physicians must be informed, equipped, and incentivized to determine who is at risk for dementia. They must be able to diagnose dementia early, so that appropriate lifestyle changes for those at risk can be recommended and the right disease-modifying drug can be delivered to the right patient at the right time in the course of the disease pathology.

Second, public and private payers must adopt across-the-board policies to incentivize physicians to perform risk assessments and dementia diagnoses in a timely fashion. To its credit, Medicare has now determined to treat Alzheimer's as a chronic disease like diabetes, COPD, and cancer, and to pay Medicare Advantage (MA) providers a bonus for every MA patient diagnosed with dementia, starting in January 2020 [11]. This is a potentially transformative development and will invest billions of dollars in early detection and diagnosis in the coming years. Unfortunately, 
Medicare has not yet committed to provide those incentives to the twothirds of beneficiaries in traditional fee-for-service Medicare.

Third, patients must learn how important it is to ask doctors about an annual cognitive assessment. Patients who demand a brain health checkup from their doctors can work as a force to create positive change in our healthcare system.

Fourth, to assure that individuals have access to innovative medicines at an affordable price, Medicare and pharmaceutical companies will need to provide accessible, easy-to-use tools to diagnosis the disease and to keep co-pays and deductibles at a level all Americans can afford. This especially includes low-income populations and communities of color who are less likely to interact with the healthcare system but more likely to have the disease.

In future issues of AGMR, UsAgainstAlzheimer's intends to look at the emerging issues in Alzheimer's from the perspective of what matters most to patients and caregivers; the urgent need for clinical trials to include more women, African Americans and Latinos; and the increasing importance of early intervention and prevention even as research continues to search for effective treatments.

These are not theoretical issues. At a time when there hasn't been a new Alzheimer's drug in 15 years, a paradigm shift is required now more than ever. Alzheimer's is not like other diseases, and therefore a "business as usual" approach to development and distribution of an effective therapy must be reexamined with added urgency. There is simply no time to develop a cure and then build a system that supports it.

In light of a rapidly aging population, the nation must simultaneously pursue pharmacological and non-pharmacological means to treat or prevent Alzheimer's; a national commitment to early intervention; and an overhaul to the healthcare system that will ensure treatments and cures are available to the right patients at the right time.

This optimal system of care will move our nation and the world closer to a state of system readiness commensurate with the gravity and growing magnitude of this public health crisis.

\section{CONFLICTS OF INTEREST}

The author holds financial interests in CosmosID and Brainscope and a very nominal interest in Chase Allergan. Interests in United Neuroscience and Brain Trust Accelerator II Fund are owned as part of family trusts.

\section{REFERENCES}

1. Roanoke Valley-Valley-Alleghany Regional Commission. AGE WAVE STUDYDemographic Analysis of the RVARC Region. Available from: https://www.rvarc.org/wp-content/uploads/2013/10/age-wave-draft.pdf. Accessed 2020 Feb 8. 
2. Causes Alzheimers Disease-What Causes Alzheimer's Disease? Available from: $\quad$ https://www.nia.nih.gov/health/what-causes-alzheimers-disease. Accessed 2020 Feb 8.

3. Alzheimer's Disease Facts and Figures. Available from: https://www.alz.org/alzheimers-dementia/facts-figures. Accessed 2020 Feb 08.

4. Taylor NP. Lawmakers propose $7 \%$ increase in NIH funding. Available from: https://www.fiercebiotech.com/biotech/lawmakers-propose-7-increase-nihfunding. Accessed 2020 Feb 8.

5. Research Progress-Treatment Horizon. Available from: https://www.alz.org/alzheimers-dementia/research progress/treatmenthorizon. Accessed 2020 Feb 8.

6. National Academies of Sciences, Engineering, and Medicine; Health and Medicine Division; Board on Health Sciences Policy; Committee on Preventing Dementia and Cognitive Impairment; Downey A, Stroud C, Landis S, et al., editors. Preventing Cognitive Decline and Dementia: A Way Forward. Washington (DC, US): National Academies Press (US); 2017.

7. A Call for Action-Creating an Optimal System of Brain Health Care in the United States. Available from: https://www.usagainstalzheimers.org/sites/default/files/201905/BrainHealthOptimalSystemFINAL.pdf. Accessed 2020 Feb 8.

8. Preventing Alzheimer's Disease. Available from: https://www.helpguide.org/articles/alzheimers-dementia-aging/preventingalzheimers-disease.htm. Accessed 2020 Feb 8.

9. The Lancet Neurology. Pointing the way to primary prevention of dementia. Lancet Neurol. 2017 Sep;16(9):677. doi: 10.1016/S1474-4422(17)30256-9

10. Biogen Plans Regulatory Filing for Aducanumab in Alzheimer's Disease Based on New Analysis of Larger Dataset from Phase 3 Studies. Available from: https://investors.biogen.com/news-releases/news-release-details/biogenplans-regulatory-filing-aducanumab-alzheimers-disease. Accessed 2020 Feb 8.

11. Vradenburg G, Dwyer J. When It Comes to Alzheimer's, Important Changes Are Coming for MA Beneficiaries. Available from: https://morningconsult.com/opinions/when-it-comes-alzheimers-importantchanges-coming-ma-beneficiaries/. Accessed 2020 Feb 8.

How to cite this article:

Vradenburg G. A Rapidly Aging Population Requires an Optimal System of Care to Stop Alzheimer's Disease. Adv Geriatr Med Res. 2020;2(2):e200009. https://doi.org/10.20900/agmr20200009 